\title{
Suspected Caprine Arthritis-Encephalitis (CAE) in a Boer cross Kid: A Case Report
}

\author{
${ }^{1}$ Chai Hui Ling, ${ }^{1,2 *}$ Faez Firdaus Jesse Abdullah, ${ }^{1,5}$ Lawan Adamu, ${ }^{1}$ Abdinasir \\ Yusuf Osman, ${ }^{4}$ Dayang Norhaizum Awang Kamaludin, ${ }^{4}$ Noorashimah \\ Roslim, ${ }^{1}$ Taqiyuddin, ${ }^{3}$ Mohd Zamri-Saad, 1 , 2 Abdul Wahid Haron, and \\ ${ }^{1}$ Abdul Aziz Saharee \\ ${ }^{1}$ Department of Veterinary Clinical Studies, Faculty of Veterinary Medicine, Universiti Putra Malaysia, 43400 \\ Serdang, Selangor, Malaysia, ${ }^{2}$ Research Centre for Ruminant Disease, Universiti Putra Malaysia, 43400 \\ Serdang, Selangor, Malaysia, ${ }^{3}$ Department of Veterinary Pathology and Microbiology, Faculty of Veterinary \\ Medicine, Universiti Putra Malaysia, 43400 Serdang, Selangor, Malaysia, ${ }^{4}$ University Veterinary Hospital, \\ Universiti Putra Malaysia, 43400 Serdang, Selangor, Malaysia, ${ }^{5}$ Department of Veterinary Medicine, Faculty of \\ Veterinary Medicine, University of Maiduguri, PMB1069, Borno State, Nigeria
}

\begin{abstract}
A 1 week old male Boer cross breed goat weighing $3 \mathrm{~kg}$ was managed intensively in a cemented enclosure. The case was presented to the Ambulatory Unit of the Large Animal Ward, University Veterinary Hospital (UVH), Universiti Putra Malaysia. The kid was fed with colostrum. The patient was presented with swollen knee joint on both forelimbs, series of intermittent seizures, paddling, opisthotonus and torticollis. There was also loss of menace response and pupillary light reflex which indicates loss of sight of both eyes. The kid died and post mortem was conducted with the findings of severe congestion of the brain and spinal cord, mild congestion of the lung, kidney, liver and gastrointestinal tract. There were swelling of the knee joint of both forelimbs and suppurative synovial fluids. Histology revealed there were severe generalised congestion of the lung, brain and spinal cord. There were thickening of the intra-alveolar septa with some inflammatory cells and evidence of spongiosis in the central nervous system.
\end{abstract}

Keywords: Kid, Caprine Arthritis-Encephalitis (CAE), post-mortem, diagnosis, histology,

\section{Introduction}

Caprine Arthritis-Encephalitis (CAE) is a multisystemic persistent viral disease of goat caused by caprine arthritis-encephalitis virus (CAEV), a lentivirus of family retroviridae [1,17]. Although most infections are subclinical, a minority of animals develops progressive, untreatable disease syndromes including polyarthritis in adults and encephalomyelitis in kids. The original lesions of CAE have extended beyond its name encompassing abnormalities in the udder, lungs and kidneys [2]. CAEV is closely related to the viruses that cause Ovine Progressive Pneumonia (OPP) and meadi-visna in sheep, and together these are referred to as small ruminant lentiviruses (SRLVs) [3, 18]. The ability of lentiviruses to cause lifelong infections is due to their tropism for cells of the immune system, particularly cells of monocyte-macrophage lineage $[4,19]$. Due to its persistent nature despite high antibody titre, it can cause losses to the goat industries by reduction in milk production caused by indurative mastitis and culling of animals, particularly when the prevalence of infection is high within a herd $[5,16]$. CAEV is widespread among dairy goats in most industrializes countries such as Canada, Norway, Switzerland, France and USA. Seropravalence of CAEV is more than $65 \%[6,10]$. The first reported definite case of CAE outbreak in Malaysia is in 2010; however since then there are no data being collected [7].

\section{Case History}

Klutzy is a 1 week old male Boer cross kid weighing $3 \mathrm{~kg}$. Vaccination and deworming was not done. The kid was kept in a cemented enclosure with its dam. It was born on $10^{\text {th }}$ July 2013, and the caretaker noticed that the Kid wasn't standing and suckling from its dam. So the kid was fed with milked colostrum from its dam. Over the days, the Kid was standing with an abnormal stance and had progressively become weak, inappetance and on sternal recumbency. Physical examination upon presentation revealed that the temperature was hypothermic $\left(35.8^{\circ} \mathrm{C}\right)$, whereas the heart rate and respiration rate were within normal ranges. The patient was presented with swollen knee joint on both forelimbs, series of intermittent seizures, paddling, opisthotonus and torticollis (Figure 1). There was also loss of menace response and pupillary light reflex which indicates loss of sight of both eyes. It was dull and depress with constant painful vocalisation. Mucous membrane was pale, and the capillary refill time (CRT) was normal, however the skin tent showed dehydration of $8 \%$. 


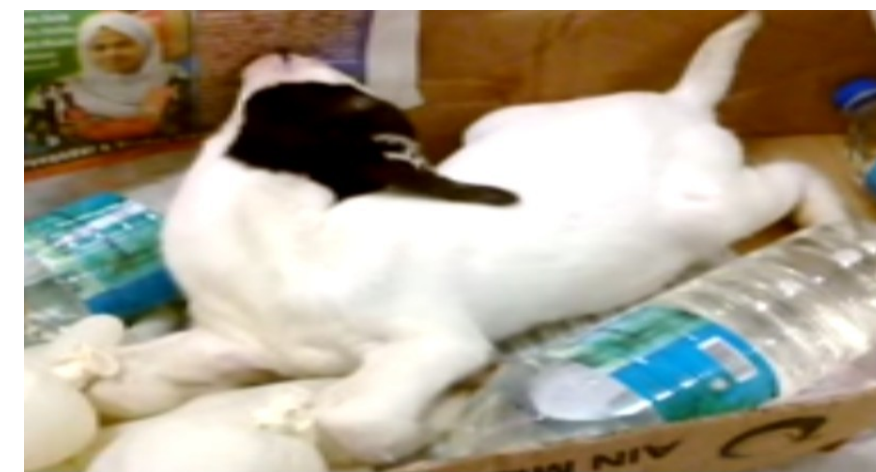

Figure 1: Animal showing torticollis and on sternal recumbency.

III. Treatment and Follow-Up

Medications given were mainly for supportive purposes to ease the neurological signs as well as to correct the dehydration status. Oral glucose G5, $30 \mathrm{ml}$ was given to treat possible hypoglycemia as the kid was having seizure and hypothermia. Methylcobal (methylcobalamine), $0.1 \mathrm{ml}$, IM and flunixin meglumine, $2.2 \mathrm{mg} / \mathrm{kg}, 0.15 \mathrm{ml}$, IM was administered as nerve supplement and NSAIDs was as well administered. To correct the $8 \%$ dehydration, Lactated Ringer's solution was administered, $120 \mathrm{ml}$ on each side subcutaneously. Catosal (a multivitamin supplement) $0.5 \mathrm{ml}$ was administered SQ, as the kid was inappetance and off-fed. As for the swollen knee joint, Betamox LA (Amoxicillin), $15 \mathrm{mg} / \mathrm{kg}, 0.3 \mathrm{ml}$, was administered IM as an empirical antibacterial in case of septic arthritis. Warm water bags were given to correct the hypothermia and to raise its temperature back to normal. The animal responded to the medication within an hour however after 4 hours it took a worse turn, had multiple seizures and died.

\section{Clinical Work-ups}

Post mortem was conducted and the findings divulged severe congestion of the brain and spinal cord (Figure 2,3), mild congestion of the lung, kidney, liver and gastrointestinal tract (Figure 4). There were swelling of the knee joint of both forelimbs and suppurative synovial fluids (Figure 5). Besides that, there was also jellylike subcutaneous tissue at the trunk due to fat necrosis as a result of starvation (Figure 6). Samples of the lung, brain and spinal cord was sent to laboratory for histology. The results revealed that there were severe generalised congestion of the lung, brain and spinal cord (Figure 7).

There was thickening of the inter-alveolar septa with some inflammatory cells in the lung (Figure 8) and evidence of spongiosis and vacuolisation (Figure 9) in the central nervous organs. Besides that, there were also presence of red neuron (Figure 10) and evidence of vasculitis in the cerebrum.

Consequently, based on the history, clinical signs, post mortem as well as histology, a presumptive diagnosis of Caprine Arthritis-Encephalitis was made.

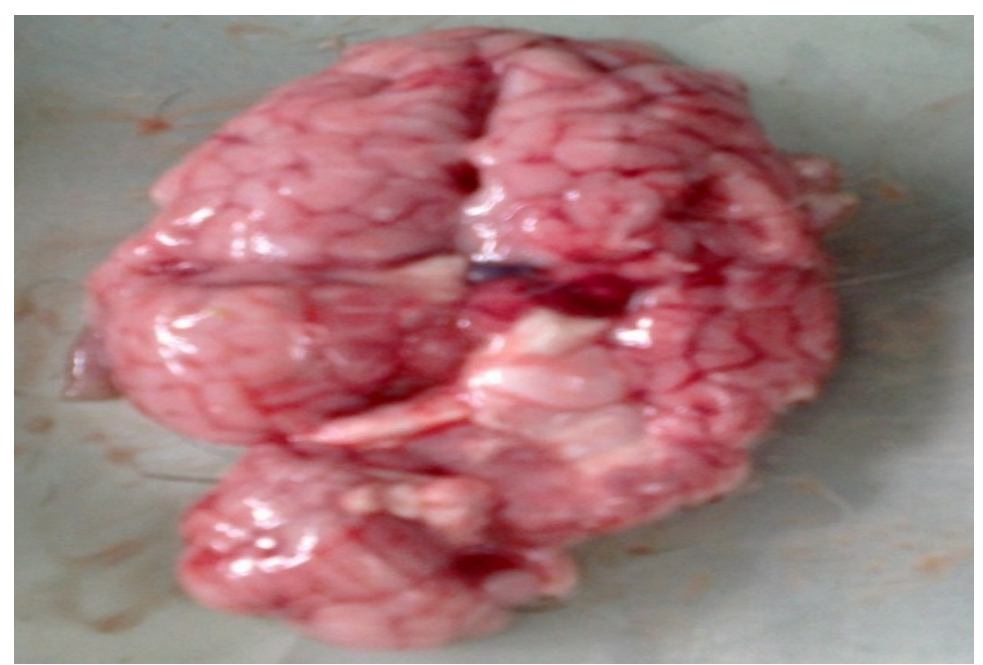

Figure 2: Congestion of the brain. 

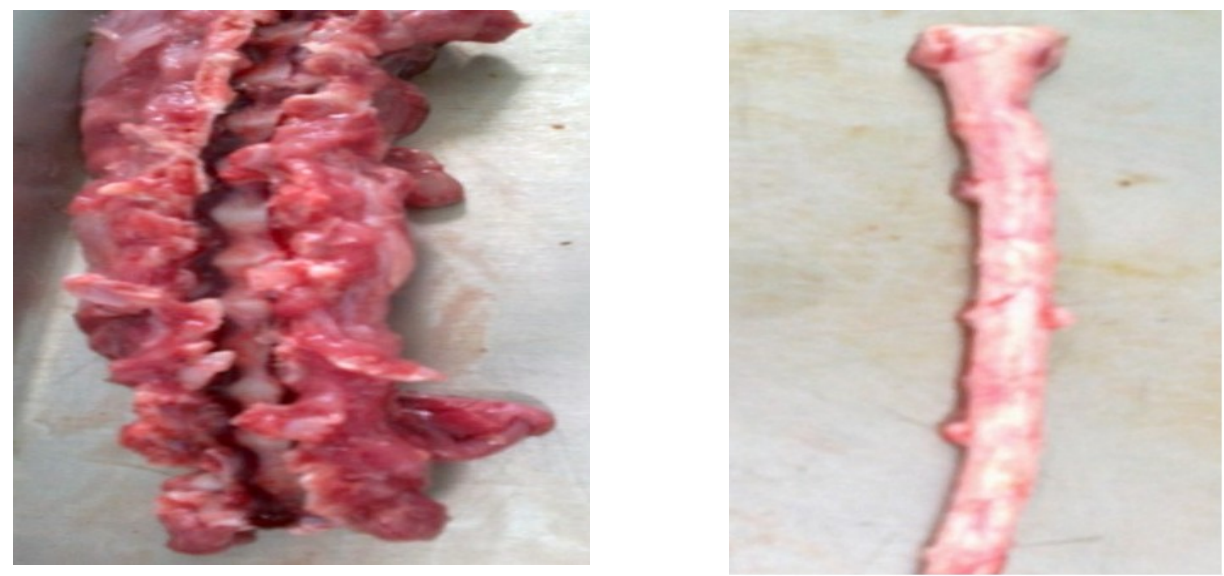

Figure 3: Congestion and swelling of the spinal cord.

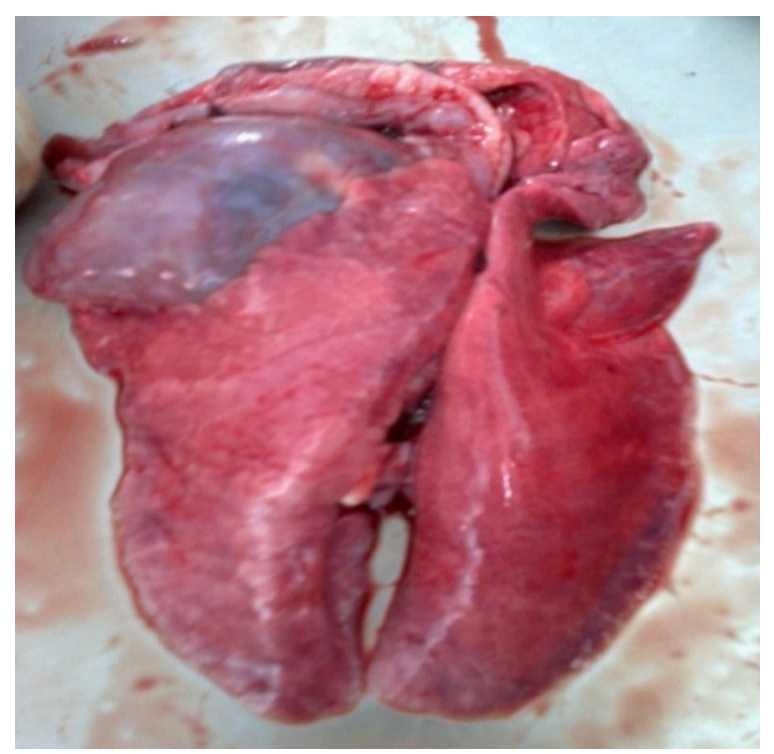

Figure 4: Mild congestion of the lung.

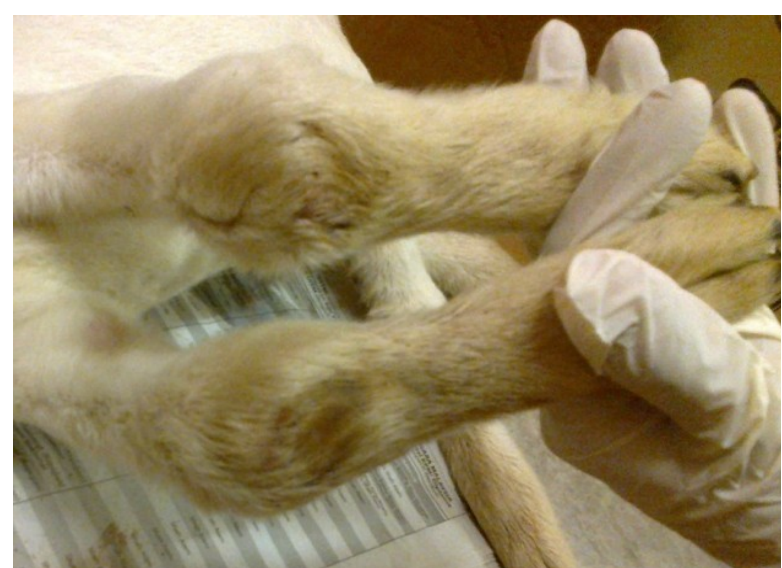

Figure 5: Swelling of the knee joint of both forelimbs. 


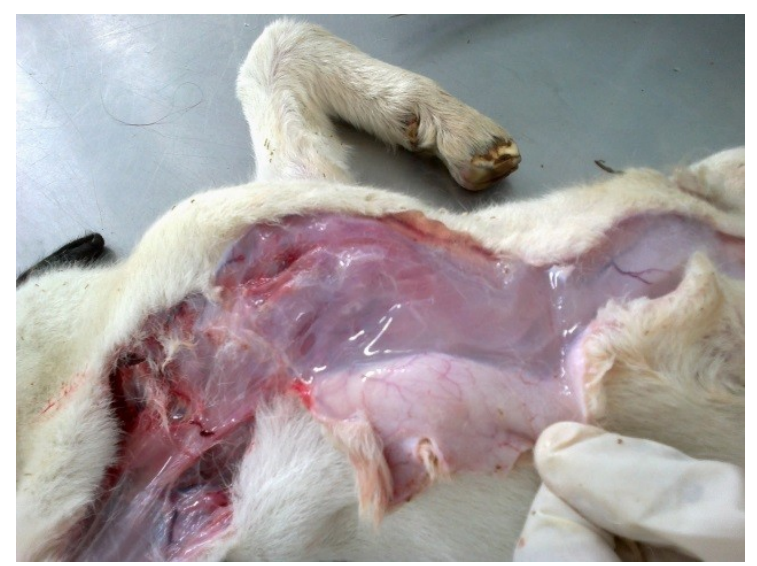

Figure 6: Jelly-like subcutaneous tissue.

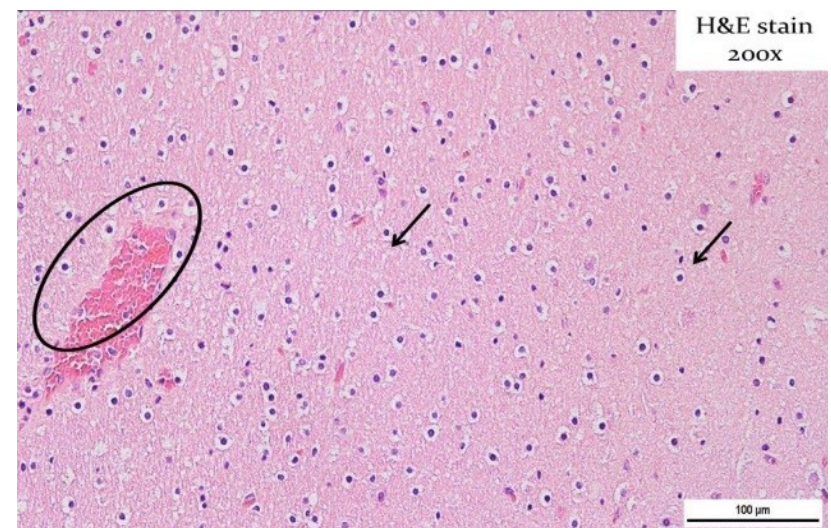

Figure 7: Generalized congestion of the brain.

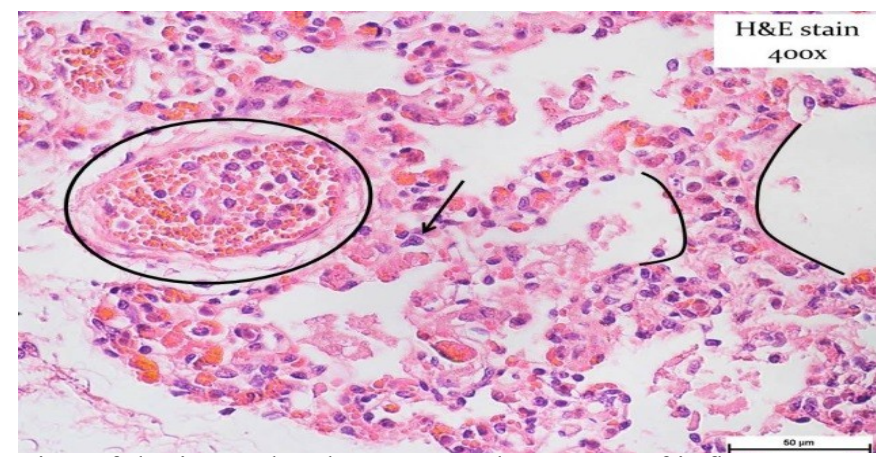

Figure 8: Thickening of the intra-alveolar septa and presence of inflammatory cells in the lung.

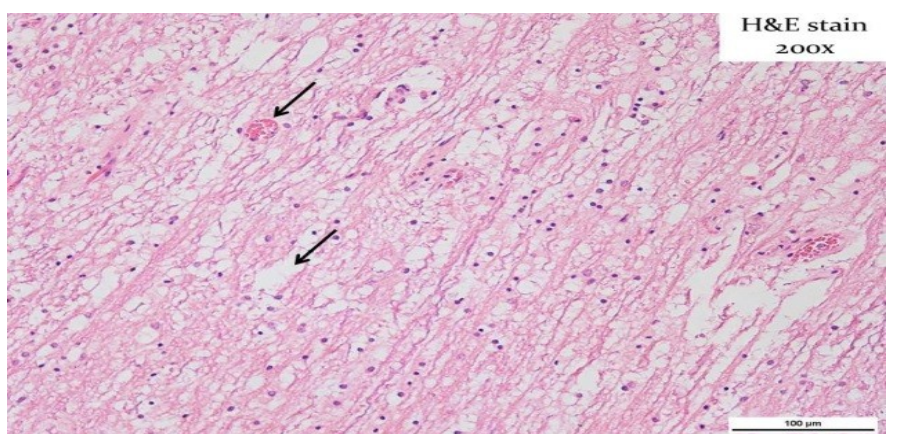

Figure 9: Spongiosis and vacuolisation of the spinal cord. 


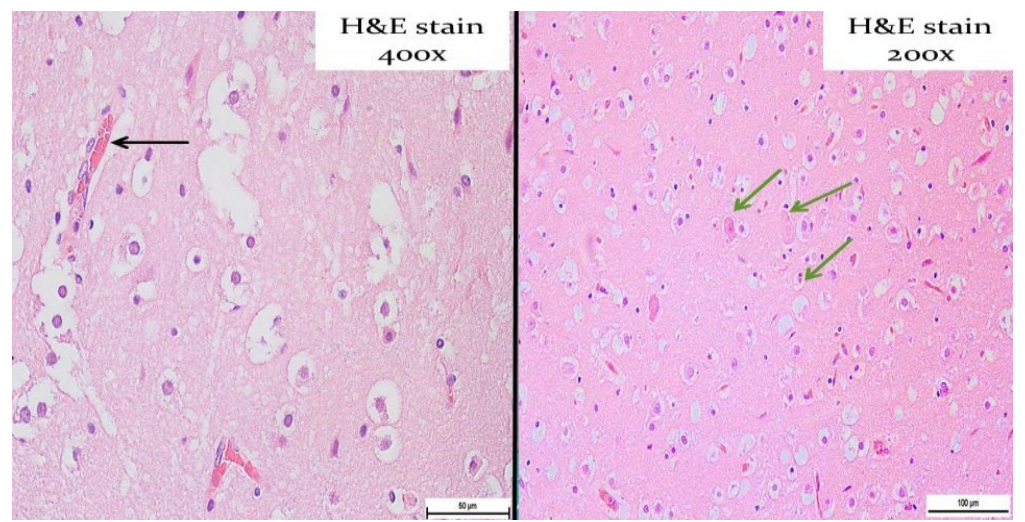

Figure 10: Presence of red neuron and vasculitis in cerebrum.

\section{Diagnostic Methods}

\section{Discussions}

There are many diagnostic methods to confirm this disease; however clinical signs, history, post mortem and histological examination of the tissue were sufficient enough to come out with a presumptive diagnosis. CAE should be suspected in adults with polyarthritis and/or indurative mastitis, and kids with progressive paresis [5]. As for this case, based on the history that the dam had an episode of indurative mastitis and after consuming colostrum and milk from the dam, the Kid developed progressive neurological signs and swollen joints, as well as from the histology results, a presumptive diagnosis of CAE was made [15].

To achieve confirmatory diagnosis, tests such as identification of the agent, nucleic acid recognition methods and serological tests can be done. Virus isolation can be done by culturing peripheral blood or milk leukocytes with appropriate caprine cells such as synovial membrane cells. The cytopathic effects are characteristics, consisting of the appearance of refractile stellate cells and syncytia. The presence of CAEV can be confirmed by immunolabelling methods and electron microscopy. As for nucleic acid recognition methods, many standard and a few quantitative polymerase chain reaction (PCR) assays have been described and are now being used routinely in many laboratories for rapid detection, quantitation and identification of the small ruminant lentivirus strains. Cloning and/or sequencing PCR products are the most direct method. This disease can also be diagnosed using serological testing that can detect specific antibodies against the virus. Agar gel immunodiffusion (AGID) and enzyme -linked immunosorbent assay (ELISA) are the most commonly used serological test, while western blot analysis and radio-immunoprecipitation are also performed, but only in specialised laboratories. The time required for seroconversion following infection can be relatively prolonged and unpredictable, being measures in months rather than in weeks. However, after seroconversion, the antibody response usually persists [8].

\section{Treatment Options}

Encephalomyelitis or polyarthritis is progressive and untreatable once these syndromes appear. Most affected goats are eventually culled for welfare or economic reasons, or die from secondary causes. Only supportive therapy can make affected goats more comfortable. Measures may include administration antiinflammatory and analgesia [5]. Young goats suffering from encephalomyelitis may benefit from physiotherapy if they area recumbent, and

\section{Prevention and Control}

Should a whole-flock blood test indicate that a flock is free from CAE infection; the owner can keep it free by practicing strict biosecurity in farm. That includes prevention of contact from sheep to prevent crossspecies infection. If a flock is infected with CAE, eradication may be achieved by regular, methodical serological testing, culling of test-positive goats and raising newborn kids in total isolation from the main flock. It is advisable to conduct serological testing twice yearly. Because CAEV is transmitted mainly through the colostrum and milk, it is possible to build-up a CAE free flock by removing kids from does immediately after birth, before the doe has the chance to groom or suckle the kid [14]. The kid must then be raised on colostrum and milk obtained from cows or CAE free does. We can also feed the kid with pasteurized colostrum or milk that has been treated at $56^{\circ} \mathrm{C}$ for at least 30 minutes $[9,11-12]$. Lentiviruses are susceptible to lipid solvents, periodate, phenolic disinfectants, formaldehyde and low pH [13]. Phenolic or quaternary ammonium compounds have been recommended for the disinfection of equipment shared between seropositive and seronegative herds [5]. 


\section{References}

[1]. Robinson, W.F. \& Ellis, T.M. (1986). Caprine Arthritis-encephalitis virus infection: from recognition to eradication. Aust. Vet. J. $63,237-241$.

[2]. Cork, L.C., Hadlow, W.J., Crawford, T.B., Gorham, J.R. \& Piper, R.C. (1974). Infectious leukoencephalomyelitis of young goats. J. Infect. Dis., 129, 134-141.

[3]. Banks, K.L., Adams, D.S., McGuire, T.C. \& Carlson J. (1983). Experimantal infection of sheep by caprine arthritis-encephalitis virus and goats by progressive pneumonia virus. Am. J. Vet. Res. 44, 293-297.

[4]. Zink, M.C., Yager, J.A. \& Myers, J.D. (1990). Pathogenesis of caprine arthritis-encephalitis virus: cellular localization of viral transcripts in tissue of infected goats. Am. J. Pathol., 136, 843-854.

[5]. Iowa State University (2007). Caprine arthritis-encephalitis, Small ruminant lentivirus infection.

[6]. The Merck Veterinary Manual [online]. Whitehou se Station, NJ: Merck and Co; 2012. Caprine arthrtitis and encephalitis.

[7]. Noordin, M.M., Ragavan, K., Shahirudin, S., Azam-Khan, G.K., Zeenathul, A., Arshad, A.A. \& Kamarudin, A.I. (2010). Emerging diseases of goats in Malaysia. Pertanika J. Trop. Agric. Sci., 33(1), 123-126.

[8]. World Organization for Animal Health [OIE]. Manual of diagnostic tests and vaccines [online]. Paris: OIE; 2008. Caprine arthritis/encephalitis and meadi-visna. Available at: $h$ htp://www.oie.int/eng/normes/mmanual/A 00071.htm.

[9]. Adams, D.S., Klevjer-Anderson, P., Carlson, J.L., McGuire, T.C. \& Graham, J.R. (1983). Transmission and control of caprine arthritis-encephalitis virus. Am. J. Vet. Res., 44, 1670-1675.

[10]. Kahn, C.M., Line, S. editors. The Merck Veterinary Manual [online]. Whitehouse Station, NJ: Merck and Co; 2003. Caprine arthrtitis and encephalitis. Available at: http://www.merckvetmanual.com/mvm/index.jsp?cfile $=\mathrm{htm} / \mathrm{bc} / 55000 . \mathrm{htm}$

[11]. Bertoni, G. (2007). Caprine arthritis-encephalitis complex.

[12]. Blacklaws, B.A., Berriatua, E., Torsteinsdottir, S., Watt, N.J., de Andres, D., Klein, D. \& Harkiss, G.D. (2004). Transmission of Small Ruminant Lentiviruses. Veterinary Microbiology 101, 199-208.

[13]. Narayan, O. \& Clements, J.E. (1989). Biology and pathogenesis of lentiviruses. J. Gen. Virol, 70, 1617 -1639

[14]. Rowe, J.D. \& East, N.E. (1997). Risk Factors for transmission and methods for control of caprine arthritis-encephalitis virus infection. Vet. Clin. North. Am. Food Anim. Pract. 13, 35-53.

[15]. Ellis, T., Robinson, W. \& Wilcox, G. (1983) Effect of colostrum deprivation of goat kids on the natural transmission of caprine retrovirus infection. Aust. Vet. J. 60, 326-329.

[16]. Carwford, T.B., Adams, D.S. (1981). Caprine arthritis-encephalitis: clinical features and presences of antibodies in selected goat populations. J. Am. Vet. Med. ASSn., 1978, 713-719

[17]. MacDiarmid, S.C. (2011). Caprine arthritis encephalitis. N.Z. Vet. J., 32, 165-166.

[18]. Zanoni, R.G. (1998). Phylogenetic analysis of small ruminant lentiviruses. J. Gen. Virol. 79, 1951-1961.

[19]. Pugh, D.G. \& Baird, A.N. (2012). Sheep \& goat Medicine, $2^{\text {nd }}$ Ed. Elsevier Saunders: Missouri. 303-304, 376-377, 497-498. 